\title{
Continuous Heterogeneously Catalyzed Oxidation of Benzyl Alcohol in a Ceramic Membrane Packed-Bed Reactor
}

\author{
Achilleas Constantinou, ${ }^{\dagger, \mathrm{Il}}$ Gaowei $\mathrm{Wu}{ }^{\dagger}$ Albert Corredera, ${ }^{\dagger}$ Peter Ellis, ${ }^{\dagger}$ Donald Bethell, ${ }^{\S}$ \\ Graham J. Hutchings, $"$ Simon Kuhn, ${ }^{\perp}$ and Asterios Gavriilidis ${ }^{*}{ }^{\dagger}$ \\ ${ }^{\dagger}$ Department of Chemical Engineering, University College London, Torrington Place, London, WC1E 7JE, United Kingdom \\ ${ }^{\mathbb{T}}$ Division of Chemical and Petroleum Engineering, School of Engineering, London South Bank University, London, SE1 0AA, United \\ Kingdom \\ ${ }^{\ddagger}$ Johnson Matthey, Blounts Court Road, Reading, RG4 9NH, United Kingdom \\ ${ }^{\S}$ Department of Chemistry, University of Liverpool, Crown Street, Liverpool L69 7ZD, United Kingdom \\ "School of Chemistry, Cardiff University, Main Building, Park Place, Cardiff, CF10 3AT, United Kingdom \\ ${ }^{\perp}$ Department of Chemical Engineering, KU Leuven, W. de Croylaan 46, 3001 Leuven, Belgium
}

Supporting Information

ABSTRACT: A ceramic membrane reactor was investigated for the continuous catalytic oxidation of benzyl alcohol with oxygen. The reactor had a concentric configuration. An inner tube created an annulus for the catalyst packed-bed ( 0.9 wt \% Au$\mathrm{Pd} / \mathrm{TiO}_{2}$, particle size 90-125 $\mu \mathrm{m}$ ) through which the liquid phase (benzyl alcohol, neat or dissolved in $o$-xylene) flowed. This was followed by the tubular ceramic membrane, which consisted of layers of alumina and a zirconia top layer with a nominal average pore size of $50 \mathrm{~nm}$. The role of the membrane was to provide an interface for gas and liquid to come in contact. Pure oxygen was fed to the opposite side of the membrane in the outer shell of the reactor. Temperature affected conversion but not selectivity, possibly because of insufficient supply of oxygen. However, increasing catalyst contact time or decreasing benzyl alcohol concentration improved selectivity and conversion, indicating that a key parameter was the balance between oxygen supply by the membrane vs oxygen demand by the reaction. By adjusting the operating parameters, reaction performance improved. Selectivity to benzaldehyde $88 \%$ and conversion of benzyl alcohol $75 \%$ were obtained at 3.2 bara of gas pressure, $24444 \mathrm{~g}_{\text {cat }} \cdot \mathrm{s} / \mathrm{g}_{\text {alcohol }}$ catalyst contact time, $0.5 \mathrm{M}$ benzyl alcohol concentration, and temperature of $120{ }^{\circ} \mathrm{C}$. This performance was comparable to simulated trickle bed operation, where oxygen and substrate were premixed before entering the catalyst packed bed. The membrane reactor offers safer operation, since flammable oxygen/organic mixtures formed in the trickle bed are avoided.

\section{INTRODUCTION}

Aldehydes, produced by catalytic oxidation of alcohols, are valuable precursors for the production of pharmaceutical compounds, dyes and fragrances. ${ }^{1,2}$ Traditionally high value chemical products (fine chemicals, pharmaceuticals) are manufactured in batch units, generating enormous waste and the direct contact of the phases raises safety concerns for hazardous reactions such as oxidations. ${ }^{3}$ Continuous processing can facilitate safe manipulation of potentially hazardous reagents by minimizing local inventory of hazardous materials and allowing efficient heat transfer in highly exothermic processes.

Membrane contactors allow two phases to come into direct contact with each other to achieve efficient interfacial mass transfer, without the need to disperse one phase into the other. The concept of using membranes covers many industrial processes such as extraction, stripping, and absorption. ${ }^{4-6}$ They can also be employed for catalytic reactions, since the membrane can either be catalytic itself or can be used to contain a catalyst particle packed-bed. ${ }^{7,8}$ Ceramic membranes have great potential for gas-liquid-solid reactions in continuous flow due to their chemical resistance and gas permeability. ${ }^{9,10}$ They allow controlled dosing of gas reactants, which can affect product selectivity. Various studies have been performed for multiphase reactions with catalytic membranes (i.e., where the catalyst is located in the membrane itself). Vospernik et al. ${ }^{11}$ used ceramic membranes, impregnated with Pt for liquid phase oxidation of aqueous formic acid solutions. The ceramic membranes consisted of multiple layers of $\mathrm{Al}_{2} \mathrm{O}_{3}$ / $\mathrm{TiO}_{2}$ and a thin layer of $\mathrm{ZrO}_{2}$, located on the inner surface of membrane, having a thickness of $\sim 6 \mu \mathrm{m}$ and a nominal average pore size of $20 \mathrm{~nm}$. Experiments and modeling showed that only a small fraction of the deposited Pt takes part in the reaction. Furthermore, the productivity of the reactor was affected by the dissolved oxygen in the reaction area and the molar ratio of reactants. Aran et al. ${ }^{12}$ examined the performance of ceramic membrane reactors varying characteristic length, catalyst support thickness, wetting properties, and operational parameters for the hydrogenation of nitrite ions $\left(\mathrm{NO}_{2}^{-}\right)$in water. The membrane consisted of $\alpha-\mathrm{Al}_{2} \mathrm{O}_{3}$ and $\gamma-\mathrm{Al}_{2} \mathrm{O}_{3}$ as a support for a $\mathrm{Pd}$ catalyst. The reaction rate per active catalyst surface area decreased by increasing the $\gamma-\mathrm{Al}_{2} \mathrm{O}_{3}$ thickness indicating internal mass transfer limitations, whereas decreasing

Received: July 5, 2015

Published: December 11, 2015 
the inner tube diameter and using slug flow in the reactor channel improved the external mass transfer. Pashkova et al. ${ }^{13}$ investigated the synthesis of hydrogen peroxide directly from hydrogen and oxygen in a gas-liquid ceramic membrane reactor. Different membrane materials were used such as $\mathrm{Al}_{2} \mathrm{O}_{3}$, $\mathrm{TiO}_{2}$, and carbon-coated $\mathrm{Al}_{2} \mathrm{O}_{3}$ with a Pd catalyst deposited into the finest porous layer on the inner side of the membranes. It was found that the diffusive transport of the reactants to the catalytically active zone, located on the inner walls of the membrane channel was crucial. Furthermore, important process parameters such as solvent type, system pressure, and flow regime were evaluated showing that ceramic membrane reactors might be suited for $\mathrm{H}_{2} \mathrm{O}_{2}$ production. Iojoiu et al. ${ }^{14}$ studied wet air oxidation of industrial effluents in a catalytic membrane reactor. Two different ceramic membranes were used; the first one consisted of pure titania support with two intermediate layers of ceria-doped-zirconia-covered titania, and the second membrane consisted of $\alpha$-alumina/titania as support with an intermediate layer of zirconia. The catalyst $(\mathrm{Pt})$ was deposited on the inside fine layer of the membrane. The catalytic membrane reactor and the operation conditions were successfully scaled-up from lab scale to a pilot unit. The approach of impregnating the catalyst on the inner side of the ceramic membranes is beneficial in terms of oxygen mass transfer and gas-liquid contacting, although it requires defined gas-permeability properties of the ceramic membranes, which might require pore modification. ${ }^{15} \mathrm{~A}$ major drawback of the impregnated membranes is that in case of deactivation the catalyst is not exchangeable. An alternative approach is to use the ceramic membrane to contain a catalyst packed-bed. The advantages of this concept are the safety (since gas and liquid can be kept separated), and the flexibility of exchanging the catalyst in case of deactivation. Packed-bed membrane reactors have been used for gas phase catalytic reactions of hydrocarbons ${ }^{16,17}$ but not for three-phase catalytic reactions.

Aerobic oxidation of benzyl alcohol using molecular oxygen is one of the most common catalytic reaction systems studied using a variety of metal based catalysts. ${ }^{18-21}$ Hutchings' group discovered that a bimetallic catalyst of $\mathrm{Au}$ and Pd led to a 25fold enhancement in turnover frequencies compared to monometallic supported $\mathrm{Au}$ and $\mathrm{Pd}^{22}$ for oxidations of alcohols (including benzyl alcohol). A few studies investigated benzyl alcohol oxidation under flow conditions using gold-based catalysts. Cao et al. ${ }^{23}$ studied the catalytic oxidation of benzyl alcohol using $\mathrm{Au}-\mathrm{Pd} / \mathrm{TiO}_{2}$ catalyst in a silicon-glass micropacked-bed reactor. It was observed that the conversion of benzyl alcohol was comparable with the conversion found in a conventional stirred batch reactor. Wang et al. ${ }^{18}$ developed a gold-immobilized microchannel flow reactor through crosslinking of copolymer for oxidations of different alcohols. No leaching of gold was observed and the gold-immobilized capillary column could be used up to 4 days without loss of activity. Kaizuka et al. ${ }^{24}$ used $\mathrm{Au}-\mathrm{Pt}$ and $\mathrm{Au}-\mathrm{Pd}$ bimetallic nanoclusters for catalytic aerobic oxidation of alcohols in multiphase flow systems. It was found that the flow systems were superior to the batch systems in terms of both yield and selectivity. Two main pathways are suggested for the solventfree synthesis of benzaldehyde from benzyl alcohol on $\mathrm{Au}-\mathrm{Pd} /$ $\mathrm{TiO}_{2}$ catalysts, ${ }^{23,25,26}$ which are the oxidation reaction (eq 1) and the disproportionation reaction (eq 2).

$$
2 \mathrm{PhCH}_{2} \mathrm{OH}+\mathrm{O}_{2} \rightarrow 2 \mathrm{PhCHO}+2 \mathrm{H}_{2} \mathrm{O}
$$

$$
2 \mathrm{PhCH}_{2} \mathrm{OH} \rightarrow \mathrm{PhCHO}+\mathrm{PhCH}_{3}+\mathrm{H}_{2} \mathrm{O}
$$

Aerobic catalytic oxidations are avoided in industry due to safety concerns. Packed-bed membrane reactors for such applications have rarely been studied. In our previous work ${ }^{27}$ we investigated the catalytic oxidation of benzyl alcohol using $\mathrm{Au}-\mathrm{Pd} / \mathrm{TiO}_{2}$ catalyst in a Teflon AF-2400 tube-in-tube configuration. This design allowed continuous penetration of oxygen through the gas-permeable tube during the reaction, and as a result conversion was significantly improved compared to a reactor operating with an oxygen presaturated feed. In this work, we study a packed-bed porous ceramic membrane reactor for a similar catalytic system. This configuration allows continuous addition of the oxidant along the length of the reactor safely, since the gas does not come in direct contact with the organic mixture in the packed-bed area. The gas/liquid interface is stabilized at the nanoporous top membrane layer, and from there oxygen diffuses into the packed-bed liquid phase. Ceramic membrane reactors offer easier scalability, as multichannel ceramic membranes are commercially available. $^{13,14}$

\section{EXPERIMENTAL SECTION}

2.1. Catalyst Preparation. $\mathrm{Au}-\mathrm{Pd} / \mathrm{TiO}_{2}$ catalyst was prepared by impregnation, similar to the procedure described in. $^{28}$ Titania (Evonik P25, $49.5 \mathrm{~g}$ ) was suspended in $200 \mathrm{~mL}$ demineralized water by stirring. Tetrachloroauric acid solution $\left(0.061 \mathrm{~g}\right.$ of $\mathrm{HAuCl}_{4}$ solution $\left.(41.22 \mathrm{wt} \% \mathrm{Au}), 0.025 \mathrm{~g} \mathrm{Au}\right)$ and palladium nitrate solution (3.16g of $\mathrm{Pd}\left(\mathrm{NO}_{3}\right)_{2}$ solution $(15.05 \% \mathrm{Pd}), 0.475 \mathrm{~g} \mathrm{Pd})$ were added to the stirred suspension. The suspension was spray dried at $220{ }^{\circ} \mathrm{C}$ (Buchi B-290) to give a pale yellow powder which was calcined in static air at 400 ${ }^{\circ} \mathrm{C}$ for $1 \mathrm{~h}$. The product was analyzed by ICP-AES and found to contain $0.85 \mathrm{wt} \% \mathrm{Pd}$ and $0.05 \mathrm{wt} \% \mathrm{Au}$, with metal particle size 1-2 $\mathrm{nm}$ as observed by TEM. The catalyst powder was pelletized and then crushed to obtain the desired particle size fraction $(90-125 \mu \mathrm{m})$ by sieving.

2.2. Packed-Bed Membrane Reactor Setup. The reactor consisted of several concentric sections (an inner tube, a ceramic membrane tube, and an outer stainless steel tube housing the whole assembly) (see Figure 1). The inner tube (outer diameter O.D. $4 \mathrm{~mm}$, inner diameter I.D. $2.96 \mathrm{~mm}$ ) and ceramic membrane created an annulus for the catalyst packedbed, through which the liquid phase flowed. The ceramic membrane tube of length $250 \mathrm{~mm}$, O.D. $10 \mathrm{~mm}$ and I.D. $7 \mathrm{~mm}$ (Pall, Europe) consisted of layers of alumina (support layer thickness $1500 \mu \mathrm{m}$, sublayer thickness $35 \mu \mathrm{m}$ ) and a zirconia top layer with nominal average pore size $50 \mathrm{~nm}$ and thickness 8 $\mu \mathrm{m}$. Oxygen was fed to the opposite side of the membrane. The housing was made out of stainless steel (Orion Alloys, UK) with an I.D. of $12 \mathrm{~mm}$. Liquid inlet and outlet tubes were welded on the two stainless steels caps at an angle (see Figure 1b) at the two ends of the reactor. For the sealing of the membrane against the two stainless steel caps, two O-rings made of ethylene propylene diene monomer (EPDM) were used. In addition, the two ends of the membranes were glazed using enamel (Johnson Matthey, UK). Two stainless steel nuts sealed and secured the inner tube on the two stainless steel caps. For retaining the catalyst, a stainless steel frit was inserted at one end of the reactor. Packing of the catalyst was achieved by suction using a vacuum pump. The amount of catalyst used in all experiments was $440 \mathrm{mg}$. The catalyst bed length was approximately $2.2 \mathrm{~cm}$ (total length of reactor $25 \mathrm{~cm}$ ). Glass 
(a)

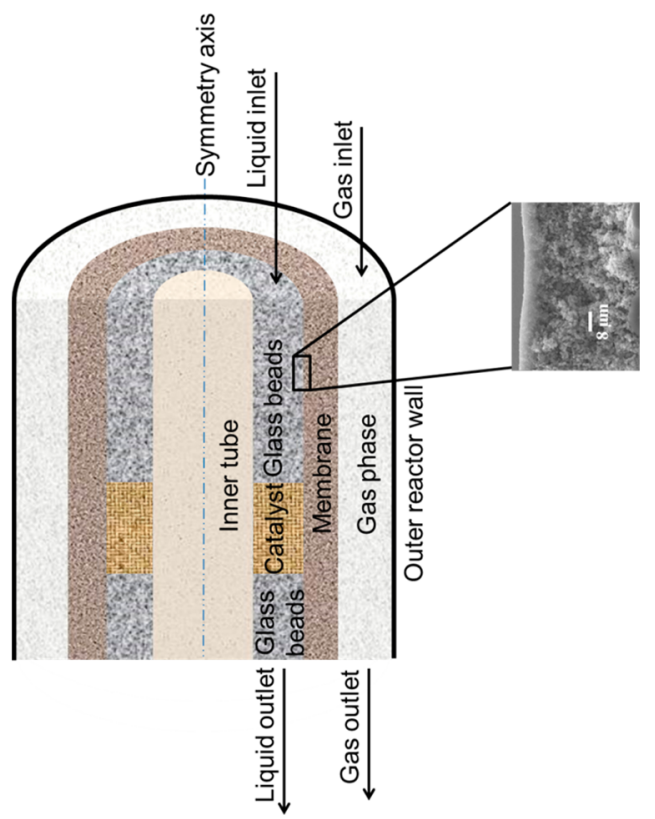

(b)

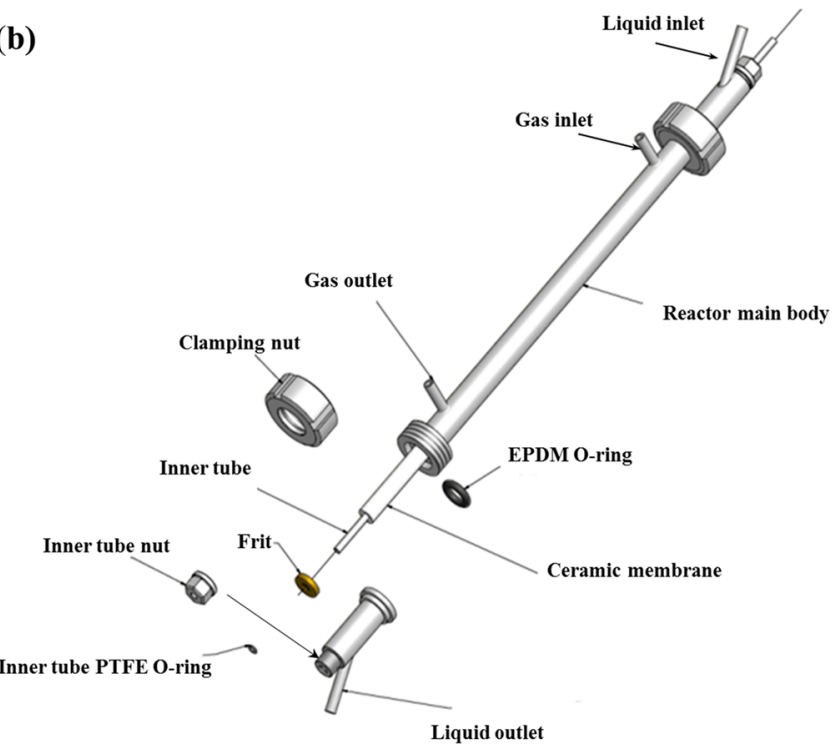

Figure 1. Schematics of membrane reactor: (a) concentric sections of the reactor (not to scale) with an SEM picture of the ceramic membrane, (b) components of the reactor assembly.

beads (100-200 $\mu \mathrm{m}, \sim 0.1 \mathrm{~g}$ ) were first sucked into the reactor creating a bed $\sim 0.5 \mathrm{~cm}$ long, followed by a layer of catalyst, after which the reactor was filled up to the top with glass beads.

A schematic of the experimental setup used for the catalytic oxidation experiments is shown in Figure 2. A HPLC pump (Vapourtec R4, UK) was used to direct the liquid benzyl alcohol (99.0\%, Sigma-Aldrich, US) in the catalyst packed-bed area, while the gas (pure $\mathrm{O}_{2}$ ) was controlled by a mass flow controller (Brooks 4800, Netherlands) and flowed on the opposite side of the membrane. The flow of liquid and gas reactants was cocurrent. Four pressure sensors (Omega, UK) were placed at the inlets/outlets of the gas/liquid phases to monitor gas/liquid pressures (all pressures reported are absolute). The differential pressure between the two phases was controlled by metering valves (Upchurch, USA) at the outlet of the liquid and gas phase after the separator. Metering valves were replaced with back pressure regulators (Zaiput,
USA) for performing experiments at 3.2 bara gas pressure. To avoid breakthrough of one phase into the other the reactor was operated with a pressure difference between the gas and the liquid phase $P_{\mathrm{G}}-P_{\mathrm{L}} \approx 0.1 \mathrm{bar}$. The outlet of the gas phase passed through a glass separator, where was diluted with pure $\mathrm{N}_{2}$ to reduce the concentration of $\mathrm{O}_{2}$ in order to avoid formation of flammable mixtures. The liquid outlet passed first through a custom-build bubble detector (based on detecting changes in the transmitted light intensity in the presence of a gas phase) and then to a liquid collector. The liquid collector was also purged with $\mathrm{N}_{2}$ to degas the solution from $\mathrm{O}_{2}$ and reduce risk. The collected sample was quantitatively analyzed by a gas chromatograph (Agilent 7820A, USA) fitted with a HP-INNOWax capillary column and a flame ionization detector.

The heating of the reactor was achieved by using three flexible heaters $\left(10 \mathrm{~W} / \mathrm{in}^{2}\right.$ each) (Omega, UK) covering the outside surface of the reactor. The heaters were insulated with calcium-magnesium silicate thermal wool (RS, UK) to reduce heat losses. Two thermocouples were placed at the inlet/outlet of the liquid phase, one in the packed-bed and one in the gas outlet to monitor the temperatures. The inclination of the inlet/outlet of the reactor allowed the insertion of the thermocouple before packing the reactor with catalyst. The temperature was measured in three different locations "a" to "c" inside the reactor (see Figure 3) by pulling up the thermocouple inside the area packed with glass beads. For the investigated temperature range no temperature gradient was observed, confirming that the reaction fluid reached the required temperature. The catalyst location toward the end of the reactor ensured that the reaction zone was isothermal. To further, check reactor isothermality, a reaction experiment was performed where the catalyst was located between " $b$ " and "c" in Figure 3. The temperature difference between the inlet and the outlet of the catalyst packed-bed was just $1^{\circ} \mathrm{C}$, which was within experimental accuracy. After the temperature tests the thermocouple was located at the location "c" shown in Figure 3. Measures to ensure safe operation of the setup are presented in the Supporting Information.

Experiments were started by setting the liquid flow rate, the reactor temperature, gas flow rate and pressure difference $\Delta P_{\mathrm{G}-\mathrm{L}}=P_{\mathrm{G}}-P_{\mathrm{L}}$ to desired values. After the system stabilized, collection of samples started. The gas flow rate was fixed at 30 $\mathrm{mL} / \mathrm{min}$, while the liquid flow rate was varied between 0.02 and $0.08 \mathrm{~mL} / \mathrm{min}$, and the reaction temperature was varied between 80 and $120{ }^{\circ} \mathrm{C}$.

Benzyl alcohol conversion $(X)$ and selectivity $(S)$ of each product were calculated based on the following equations:

$$
X=\frac{C_{\text {alcohol,in }}-C_{\text {alcohol,out }}}{C_{\text {alcohol, in }}} \times 100 \%
$$

where $C_{\text {alcohol,in }}$ and $C_{\text {alcohol,out }}$ were the concentration of benzyl alcohol at the inlet and outlet, respectively,

$$
S_{i}=\frac{C_{i} \nu_{i}}{C_{\text {alcohol, in }} X_{\text {total }}} \times 100 \%
$$

where $\nu_{i}$ was the number of moles of benzyl alcohol consumed for the production of $1 \mathrm{~mol}$ of product $i$. Catalyst contact time was used to characterize the reaction time of benzyl alcohol and was defined as 


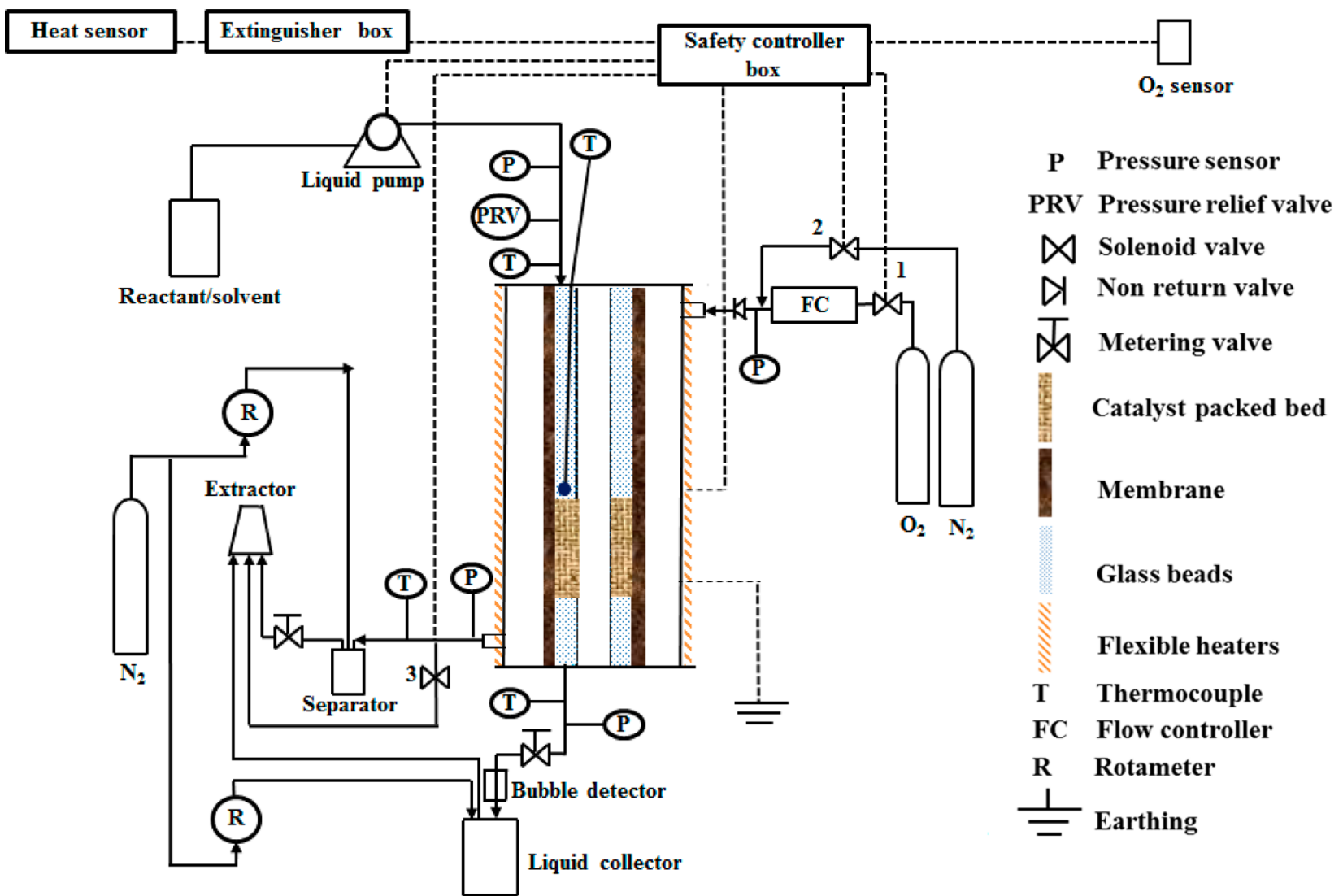

Figure 2. Schematic diagram of the experimental setup.

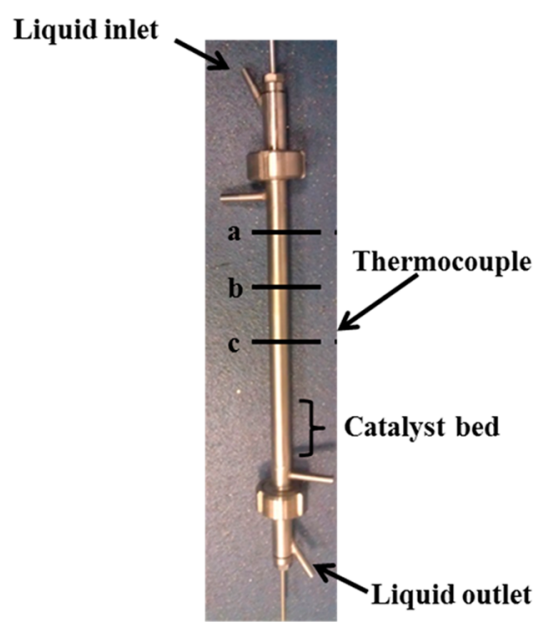

Figure 3. Picture of the ceramic membrane packed-bed reactor. Lines indicate the locations where temperature was measured with the thermocouple inside the reactor.

$$
\mathrm{CCT}=\frac{\text { mass of catalyst }\left(\mathrm{g}_{\mathrm{cat}}\right)}{\text { mass flow rate of benzyl alcohol }\left(\mathrm{g}_{\mathrm{alcohol}} / \mathrm{s}\right)}
$$

For each experiment, three samples were collected, and the results were averaged. The reproducibility of the experiments and catalyst stability were checked by a standard run $\left(100^{\circ} \mathrm{C}\right.$, catalyst space time $635 \mathrm{~g}_{\text {alcohol }} \cdot \mathrm{s} / \mathrm{g}_{\text {cat }}$ liquid flow rate $0.04 \mathrm{~mL} /$ min, gas flow rate $30 \mathrm{~mL} / \mathrm{min}$, gas pressure $1.1 \mathrm{bara})$, and the relative difference was less than $\pm 5 \%$.

\section{RESULTS AND DISCUSSION}

3.1. Effect of Temperature. Figure 4 shows the effect of temperature on benzyl alcohol conversion and selectivities to

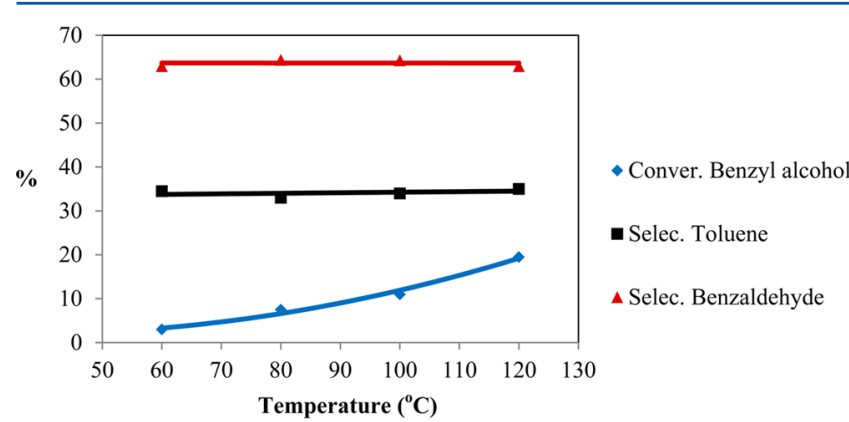

Figure 4. Effect of temperature on benzyl alcohol conversion and selectivities to toluene and benzaldehyde. Reaction conditions: gas pressure 1.1 bara, liquid flow rate $0.04 \mathrm{~mL} / \mathrm{min}$, gas flow rate $30 \mathrm{~mL} /$ min, and inlet pure $\mathrm{BnOH}$.

benzaldehyde and toluene when the temperature was changed from 60 to $120{ }^{\circ} \mathrm{C}$. Benzyl alcohol conversion increased up to $19.5 \%$ by increasing the temperature to $120{ }^{\circ} \mathrm{C}$. Despite the temperature change, selectivity to benzaldehyde changed only slightly and varied between 63 and 64\%. The same trend was observed for toluene selectivity (variation between 33 and $35 \%)$. This is in contrast to the results of Cao et al., ${ }^{23}$ where the catalytic oxidation of benzyl alcohol using $\mathrm{Au}-\mathrm{Pd} / \mathrm{TiO}_{2}$ (particle size 50-63 $\mu \mathrm{m}$, based on sol immobilization preparation method) in a silicon-glass micropacked-bed reactor resulted in increased conversion of benzyl alcohol and 
Table 1. Comparison of Benzyl Alcohol Conversion and Selectivities between Membrane and Trickle-Bed Operation ${ }^{a}$

$\begin{array}{ccccccccc}\begin{array}{c}\text { mode of } \\ \text { operation }\end{array} & X(\%) & \begin{array}{c}S_{\text {benzaldehyde }} \\ (\%)\end{array} & \begin{array}{c}S_{\text {toluene }} \\ (\%)\end{array} & \begin{array}{c}S_{\text {benzene }} \\ (\%)\end{array} & \begin{array}{c}S_{\text {dibenzyl ether }} \\ (\%)\end{array} & \begin{array}{c}S_{\text {benzoic acid }} \\ (\%)\end{array} & \begin{array}{c}S_{\text {benzyl benzoate }} \\ (\%)\end{array} & \text { oxygen consumption rate }\left(\mathrm{mol} / \mathrm{g}_{\text {cat }} \cdot \mathrm{min}\right) \\ \text { membrane } & 11 & 64 & 33.6 & 0.2 & 0.9 & 0.3 & 0.94 & 1.5 \times 10^{-5} \\ \text { trickle bed } & 29 & 77 & 17 & 0.85 & 2 & 1.3 & 1.9 & 7.6 \times 10^{-5}\end{array}$

${ }^{a}$ Reaction conditions: reactant pure benzyl alcohol, liquid flow rate $0.04 \mathrm{~mL} / \mathrm{min}$, temperature $100{ }^{\circ} \mathrm{C}$, catalyst contact time $635 \mathrm{~g}$ cat ${ }^{\circ} / \mathrm{g}_{\text {alcohol }}$. Membrane operation: gas flow rate $30 \mathrm{~mL} / \mathrm{min}$, gas pressure 1.1 bara. Trickle bed operation: gas flow rate $20 \mathrm{~mL} / \mathrm{min}$, gas pressure 1 bara.

decreased selectivity to benzaldehyde (from 85 to $61 \%$ ) when the temperature was increased from 80 to $120{ }^{\circ} \mathrm{C}$. In the micropacked-bed reactor the gas and liquid phases were mixed at the inlet (gas to liquid flow rate ratio $=100$ ), whereas in this work a gas/liquid interface was stabilized at the nanoporous top membrane layer, where the liquid was saturated with oxygen and from there oxygen diffused in the packed-bed liquid phase. No bubbles were created in the liquid that flowed inside the packed-bed. The different trend with respect to benzaldehyde selectivity with temperature might be related to insufficient supply of oxygen in the catalyst packed-bed area, but also to the different catalyst preparation method.

To further explore the importance of oxygen on conversion and selectivities, an experiment was performed in which the gas and liquid phases were mixed before entering the reactor and the gas inlet/outlet of the reactor were closed, thus simulating a trickle bed operation. The gas flow rate was $20 \mathrm{~mL} / \mathrm{min}$ with liquid flow rate $0.04 \mathrm{~mL} / \mathrm{min}$ resulting in a gas to liquid flow rate ratio of 500. Table 1 compares the results of the membrane and trickle bed operation. It is observed that for identical temperature, catalyst amount, and catalyst contact time, the conversion of benzyl alcohol $(X)$ and selectivity to benzaldehyde $\left(S_{\text {benzaldehyde }}\right)$ are higher and selectivity to toluene $\left(S_{\text {toluene }}\right)$ is lower for the trickle bed operation. For the latter, more oxygen is present in the catalyst packed-bed, and as a result the oxidation reaction (see eq 1) is enhanced. During membrane operation insufficient supply of oxygen to the catalyst packed-bed area results in decreased selectivity to benzaldehyde and benzyl alcohol conversion. Table 1 also lists selectivities to other products and for the membrane condition their values were always lower than $3 \%$. These findings seem to corroborate that the lack of sufficient oxygen is the reason for the low and constant selectivity to benzaldehyde with temperature under membrane operation. Under the operating conditions above, a trickle bed reactor is beneficial for increasing both conversion and selectivity.

3.2. Effect of Catalyst Contact Time. The effect of catalyst contact time was investigated by varying the liquid flow rate from 0.02 to $0.08 \mathrm{~mL} / \mathrm{min}$ and keeping the same amount of catalyst $(440 \mathrm{mg})$ under membrane operation. By increasing the space time from 317 to $1269 \mathrm{~g}_{\text {cat }} \cdot \mathrm{s} / \mathrm{g}_{\text {alcohol }}$ the benzyl alcohol conversion increased up to $19.2 \%$, while the selectivity to benzaldehyde increased from $59 \%$ to $69 \%$ and the selectivity to toluene decreased from $39 \%$ to $28 \%$ (Figure 5). Cao et al. ${ }^{23}$ studied benzyl alcohol oxidation in a silicon-glass micropackedbed and a batch reactor. Oxygen remained in excess in these two reactors, which may explain the reason why the selectivities to benzaldehyde and toluene remained almost the same at different catalyst contact time. In our membrane operation the differences in selectivities might be due to oxygen deficiency in the catalyst packed-bed area. By decreasing the liquid flow rate and keeping the catalyst bed length constant the catalyst contact time was increased and hence, oxygen had more time to permeate and react. This allowed increased consumption of

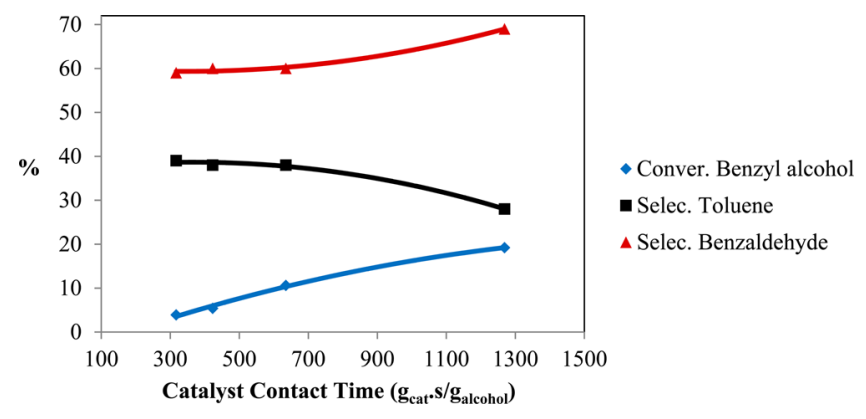

Figure 5. Effect of catalyst contact time on benzyl alcohol conversion and selectivities to toluene and benzaldehyde. Reaction conditions: gas pressure 1.1 bara, liquid flow rate $0.02-0.08 \mathrm{~mL} / \mathrm{min}$, gas flow rate 30 $\mathrm{mL} / \mathrm{min}$, inlet pure $\mathrm{BnOH}$, temperature $100{ }^{\circ} \mathrm{C}$.

oxygen by the oxidation reaction (see eq 1 ). As a result, selectivity to benzaldehyde increased with catalyst contact time. The same observation for the selectivities to benzaldehyde and toluene was reported in our previous work ${ }^{27}$ where the oxidation of benzyl alcohol was performed in a tube-in-tube configuration.

3.3. Effect of Benzyl Alcohol Dilution. To increase the oxygen supply in relation to oxygen demand by the reaction and thus improve conversion of benzyl alcohol and benzaldehyde selectivity, benzyl alcohol was diluted 5-20 times using $o$-xylene as a solvent. Figure 6 shows the results

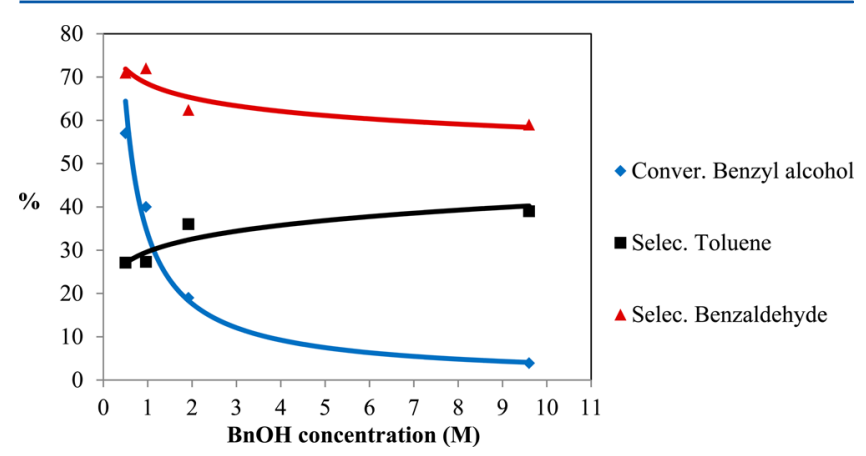

Figure 6. Effect of dilution of benzyl alcohol on benzyl alcohol conversion and selectivities to toluene and benzaldehyde. Reaction conditions: gas pressure 1.1 bara, liquid flow rate $0.08 \mathrm{~mL} / \mathrm{min}$, gas flow rate $30 \mathrm{~mL} / \mathrm{min}$, temperature $100{ }^{\circ} \mathrm{C}$.

when the concentration of benzyl alcohol was varied from 0.5 $\mathrm{M}$ to $9.6 \mathrm{M}$. Diluting benzyl alcohol 20 times resulted to conversion increase to $57 \%$. Correspondingly selectivity to benzaldehyde increased to $72 \%$, while selectivity to toluene dropped to $27 \%$. The reason for this behavior is that the oxygen supply remained the same (as in previous experiments), but the benzyl alcohol concentration was decreased. As a result, oxygen demand was less, and the oxygen supply through the membrane resulted in a higher dissolved oxygen concentration in the catalyst packed-bed area. 
Table 2. Operating Conditions for Optimizing Reaction Performance ${ }^{a}$

$\begin{array}{ccccc}\text { mode of operation } & X(\%) & S_{\text {benzaldehyde }}(\%) & S_{\text {toluene }}(\%) & \text { oxygen consumption rate }\left(\mathrm{mol} / \mathrm{g}_{\text {cat }} \cdot \mathrm{min}\right) \\ \text { membrane } & 75 & 88 & 9 & 6.7 \times 10^{-6} \\ \text { trickle bed } & 80 & 85 & 6 & 7.2 \times 10^{-6}\end{array}$

${ }^{a}$ Reaction conditions: benzyl alcohol concentration $0.5 \mathrm{M}$, liquid flow rate $0.02 \mathrm{~mL} / \mathrm{min}$, temperature $120{ }^{\circ} \mathrm{C}$, gas pressure $3.1-3.2$ bara, catalyst

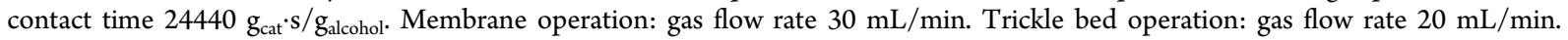

3.4. Optimized Conditions for Higher Benzaldehyde Selectivity. In a next step, operating conditions were adjusted with the aim to further increase the selectivity to benzaldehyde and the conversion of benzyl alcohol. Benzyl alcohol was diluted with $o$-xylene $(\mathrm{BnOH} 0.5 \mathrm{M})$, gas pressure was increased to 3.2 bara (upper limit for the setup), and catalyst contact time was increased to $24444\left(\mathrm{~g}_{\text {cat }} \cdot \mathrm{s} / \mathrm{g}_{\text {alcohol }}\right)$ and temperature to $120{ }^{\circ} \mathrm{C}$. Dilution of benzyl alcohol resulted in lower oxygen demand by the reaction, increasing the gas pressure increased dissolved oxygen concentration, higher catalyst contact time gave oxygen more time to permeate and react, and higher temperature resulted to a higher reaction rate. Table 2 shows that under membrane operation the conversion of benzyl alcohol increased to $75 \%$ (previous maximum $57 \%$, see Figure 6) and most importantly the selectivity to benzaldehyde increased to $88 \%$ (previous maximum $72 \%$, see Figure 6). This is a significant improvement in selectivity and conversion compared to previous results (sections 3.1-3.3). The selectivity improvement is attributed to higher oxygen concentration not only in the bulk liquid in the packed-bed but also inside the catalytic particles. The possibility of solvent influencing the selectivity cannot be excluded. As a comparison, experiments were performed under the same reaction conditions in trickle bed operation, which resulted in conversion of benzyl alcohol of $80 \%$ and selectivity to benzaldehyde of $85 \%$ (Table 2 ). This conversion and selectivity were similar to the values obtained under membrane operation, which indicates sufficient oxygen supply for both membrane and trickle bed operation.

The catalytic system studied in this work is relatively fast. For undiluted reactant and atmospheric oxygen pressure, average oxygen consumption rate is $7.6 \times 10^{-5} \mathrm{~mol} / \mathrm{g}_{\text {cat }}$ min (see Table 1) for trickle bed operation which provides the best performance. For the same conditions, the membrane reactor shows reaction rates of $1.5 \times 10^{-5} \mathrm{~mol} / \mathrm{g}_{\mathrm{cat}} \mathrm{min}$, indicating that oxygen supply is not sufficient. However, under the conditions for optimized selectivity (see Table 2 ) the oxygen reaction rates are closer: $7.2 \times 10^{-6} \mathrm{~mol} / \mathrm{g}_{\text {cat }}$ min for trickle bed operation and $6.7 \times 10^{-6} \mathrm{~mol} / \mathrm{g}_{\text {cat }}$ min for membrane operation. Hence, for benzyl alcohol oxidation on the catalyst and the membrane reactor used in this work, reaction rates need to be reduced for improving selectivity so that an acceptable balance between oxygen supply and demand is achieved. If this is acceptable, it would also depend on consideration of the safety advantages that the membrane reactor offers and the downstream separation costs. For slower catalytic systems, with oxygen reaction rates below $7 \times 10^{-6} \mathrm{~mol} / \mathrm{g}_{\text {cat }} \mathrm{min}$, the membrane reactor would be satisfactory, without having to slow down the reaction. For such systems, filling the reactor with catalyst or recirculating the liquid reactant can be utilized to increase reactant conversion.

\section{CONCLUSIONS}

A catalytic packed-bed ceramic membrane reactor was developed and used for the continuous heterogeneously catalyzed aerobic oxidation of benzyl alcohol. This reactor configuration allows continuous addition of the oxidant along the length of the reactor, and since the gas does not come in direct contact with the organic mixture in the packed-bed area, it enables safer, continuous oxidation of benzyl alcohol. In addition, it allows expedient catalyst replacement in case of deactivation which is not possible for wall-coated catalytic membrane reactors. However, the rate of oxidant supply may not be sufficient for fast reactions. Experiments showed that benzyl alcohol conversion increased with increasing temperature, catalyst contact time and dilution with $o$-xylene. The selectivity to benzaldehyde increased with catalyst contact time, since oxygen had more time to penetrate and react in the catalyst packed-bed area. The same trend was observed by diluting benzyl alcohol with $o$-xylene, since less oxygen was required by the reaction. Temperature changes had no significant effect on the selectivity to benzaldehyde possibly due to deficiency of oxygen in the catalyst packed-bed area under membrane operation. Selectivity and conversion were improved by increasing gas pressure, diluting benzyl alcohol, increasing catalyst contact time and increasing temperature. This work demonstrates that, if oxygen supply and demand are not balanced, operating and design parameters can be altered to overcome the deficiency of oxygen in the catalyst bed area.

\section{ASSOCIATED CONTENT}

\section{S Supporting Information}

The Supporting Information is available free of charge on the ACS Publications website at DOI: 10.1021/acs.oprd.5b00220.

A detailed description of safety precautions which provided several layers of safety in the experimental setup (PDF)

\section{AUTHOR INFORMATION}

\section{Corresponding Author}

*E-mail: a.gavriilidis@ucl.ac.uk.

\section{Notes}

The authors declare no competing financial interest.

\section{ACKNOWLEDGMENTS}

Financial support by EPSRC (grant EP/L003279/1) is gratefully acknowledged. We thank Simon Barrass for help with the experimental setup, John Langdon for the fabrication of the reactor, and Winson Kuo for catalyst characterisation.

\section{REFERENCES}

(1) Bäckval, J. E. Modern Oxidation Methods; Wiley-VCH: Weinheim, 2004.

(2) Hudlicky, M. Oxidation in Organic Chemistry; American Chemical Society: Washington, DC, 1990.

(3) Mannel, D. S.; Stahl, S. S.; Root, T. W. Org. Process Res. Dev. 2014, 18, 1503-1508.

(4) Cai, Z.-X.; Fang, Q.; Chen, H.-W.; Fang, Z.-L. Anal. Chim. Acta 2006, 556, 151-156. 
(5) Constantinou, A.; Ghiotto, F.; Lam, K. F.; Gavriilidis, A. Analyst 2014, 139, 266-272.

(6) Constantinou, A.; Barrass, S.; Gavriilidis, A. Ind. Eng. Chem. Res. 2014, 53, 9236-9242.

(7) Coronas, J.; Santamaría, J. Catal. Today 1999, 51, 377-389.

(8) Julbe, A.; Farrusseng, D.; Guizard, C. J. Membr. Sci. 2001, 181, 320.

(9) Vospernik, M.; Pintar, A.; Berčič, G.; Batista, J.; Levec, J. Chem. Eng. Res. Des. 2004, 82, 659-666.

(10) Aran, H. C.; Chinthaginjala, J. K.; Groote, R.; Roelofs, T.; Lefferts, L.; Wessling, M.; Lammertink, R. G. H. Chem. Eng. J. 2011, 169, 239-246.

(11) Vospernik, M.; Pintar, A.; Levec, J. Chem. Eng. Process. 2006, 45, 404-414.

(12) Aran, H. C.; Klooster, H.; Jani, J. M.; Wessling, M.; Lefferts, L.; Lammertink, R. G. H. Chem. Eng. J. 2012, 207-208, 814-821.

(13) Pashkova, A.; Dittmeyer, R.; Kaltenborn, N.; Richter, H. Chem. Eng. J. 2010, 165, 924-933.

(14) Iojoiu, E. E.; Landrivon, E.; Raeder, H.; Torp, E. G.; Miachon, S.; Dalmon, J.-A. Catal. Today 2006, 118, 246-252.

(15) Murru, M.; Prabowo, A.; Gavriilidis, A. J. Membr. Sci. 2005, 248, $27-36$.

(16) Klose, F.; Wolff, T.; Thomas, S.; Seidel-Morgenstern, A. Appl. Catal., A 2004, 257, 193-199.

(17) Oyama, S. T.; Zhang, X.; Lu, J.; Gu, Y.; Fujitani, T. J. Catal. 2008, 257, 1-4.

(18) Wang, N.; Matsumoto, T.; Ueno, M.; Miyamura, H.; Kobayashi, S. Angew. Chem. 2009, 121, 4838-4840.

(19) Zotova, N.; Hellgardt, K.; Kelsall, G. H.; Jessiman, A. S.; Hii, K. K. Green Chem. 2010, 12, 2157-2163.

(20) Kesavan, L.; Tiruvalam, R.; Rahim, M. H. A.; bin Saiman, M. I.; Enache, D. I.; Jenkins, R. L.; Dimitratos, N.; Lopez-Sanchez, J. A.; Taylor, S. H.; Knight, D. W.; Kiely, C. J.; Hutchings, G. J. Science 2011, 331, 195-199.

(21) Obermayer, D.; Balu, A. M.; Romero, A. A.; Goessler, W.; Luque, R.; Kappe, C. O. Green Chem. 2013, 15, 1530-1537.

(22) Enache, D. I.; Edwards, J. K.; Landon, P.; Solsona-Espriu, B.; Carley, A. F.; Herzing, A. A.; Watanabe, M.; Kiely, C. J.; Knight, D. W.; Hutchings, G. J. Science 2006, 311, 362-365.

(23) Cao, E.; Sankar, M.; Firth, S.; Lam, K. F.; Bethell, D.; Knight, D. K.; Hutchings, G. J.; McMillan, P. F.; Gavriilidis, A. Chem. Eng. J. 2011, 167, 734-743.

(24) Kaizuka, K.; Lee, K.-Y.; Miyamura, H.; Kobayashi, S. J. Flow Chem. 2012, 2, 1-4.

(25) Sankar, M.; Nowicka, E.; Tiruvalam, R.; He, Q.; Taylor, S. H.; Kiely, C. J.; Bethell, D.; Knight, D. W.; Hutchings, G. J. Chem. - Eur. J. 2011, 17, 6524-6532.

(26) Meenakshisundaram, S.; Nowicka, E.; Miedziak, P. J.; Brett, G. L.; Jenkins, R. L.; Dimitratos, N.; Taylor, S. H.; Knight, D. W.; Bethell, D.; Hutchings, G. J. Faraday Discuss. 2010, 145, 341-356.

(27) Wu, G.; Constantinou, A.; Cao, E.; Kuhn, S.; Morad, M.; Sankar, M.; Bethell, D.; Hutchings, G. J.; Gavriilidis, A. Ind. Eng. Chem. Res. 2015, 54, 4183-4189.

(28) Dimitratos, N.; Lopez-Sanchez, J. A.; Anthonykutty, J. M.; Brett, G.; Carley, A. F.; Tiruvalam, R. C.; Herzing, A. A.; Kiely, C. J.; Knight, D. W.; Hutchings, G. J. Phys. Chem. Chem. Phys. 2009, 11, 4952-4961. 